\title{
Cause specific social class mortality differentials for child injury and poisoning in England and Wales
}

\author{
Ian Roberts
}

Injury is the leading cause of death in children in the United Kingdom. The social class gradient for injury death is steeper than for any other cause of child death. Nevertheless, the Government publication Variations in Health makes little reference to socioeconomic variations in childhood injury mortality. ${ }^{1}$ The failure to address this important source of variation in health may be due to the lack of recent data on childhood mortality differentials. To date, the principal source of data on social class mortality differentials has been the Childhood Supplement on Occupational Mortality 1979$83 .^{2}$ However, as pointed out in Variations in Health, "accidental deaths in children have fallen to little more than half their level of around 1980, and the social class pattern may have changed". We examined social class injury mortality differentials for period 1985-92.

\begin{abstract}
Methods
A data file containing the records of all child (0-15 years) injury deaths for the period 1985-92 in England and Wales was obtained from the Office of National Statistics. 1992 is the most recent year for which data are available. Each record included the external cause of injury code ( $E$ code), and the parents occupational class. The deceased child's social class was based on the father's social class, unless this was missing, when it was based on the mother's. In the non-manual social classes the annual number of injury deaths was low and consequently class specific injury mortality rates were imprecise. To increase the precision of class specific injury mortality rates, eight year mortality rates (1985-92) were calculated. Class specific denominator data were obtained by linear interpolation using data from the
\end{abstract}

1981 and 1991 censuses. Poisson regression modelling was used to test the linear trend in injury death rates across the social classes. Using this model, the odds ratio is interpreted as the odds of death in any social class category relative to the odds of death in the preceding social class category.

\section{Results}

Children in social class $\mathrm{V}$ are 4.6 times more likely to suffer accidental death than their peers in social class I (table 1). Mortality differentials are steepest for fire related deaths and pedestrian injury deaths. For deaths due to fire and flames, the death rate for children in social class $\mathrm{V}$ is over 16 times that of children in social class I. For child pedestrian injury, the rate for children in social class $\mathrm{V}$ is five times that of children in social class I. Although there is a social class mortality gradient for every category of injury examined, the gradient was least for motor vehicle occupant injury and suicide.

\section{Discussion}

Despite the overall decline in child injury mortality, steep social class mortality differentials persist. Moreover, the results of recent analyses show that these gradients have widened. ${ }^{3} \mathrm{Be}-$ cause the annual number of injury deaths among children in the non-manual social classes is low, in order to examine mortality differentials by injury type, it is necessary to increase the time period of observation. In this way it is possible to identify that mortality gradients are steepest for deaths due to fires and deaths of children as pedestrians. This observation is particularly important because

Table 1 Death rates (deaths 100 000/8 years) and social class mortality differentials for child injury and poisoning, England and Wales, 1985-92

\begin{tabular}{|c|c|c|c|c|c|c|c|c|}
\hline \multirow[t]{2}{*}{ Cause of death } & \multirow[t]{2}{*}{ No (1985-92) } & \multicolumn{6}{|c|}{ Social class } & \multirow[b]{2}{*}{ Odds ratio $(95 \% \mathrm{CI})$} \\
\hline & & $I$ & II & IIIn & IIIm & IV & $V$ & \\
\hline All injury (E800-999) & 4825 & 34.8 & 34.7 & 45.4 & 65.6 & 79.8 & 160.6 & $1.38(1.35,1.41)$ \\
\hline Motor vehicle traffic accident (E810-819)* & 578 & 6.1 & 6.1 & 5.9 & 7.6 & 8.2 & 9.9 & $1.11(1.05,1.18)$ \\
\hline $\begin{array}{l}\text { Cyclist injured in a collision with a motor vehicle } \\
\text { (E813.6) }\end{array}$ & 349 & 2.4 & 3.0 & 3.1 & 4.8 & 5.2 & 10.7 & $1.30(1.20,1.41)$ \\
\hline $\begin{array}{l}\text { Pedestrian injured in a collision with a motor vehicle } \\
\text { (E814.7) }\end{array}$ & 133 & 19.4 & 8.0 & 9.9 & 19.7 & 23.1 & 46.5 & $1.47(1.41,1.53)$ \\
\hline Poisoning (E850-869) & 71 & 0.0 & 0.7 & 0.8 & 1.0 & 1.0 & 2.3 & $1.36(1.14,1.62)$ \\
\hline Falls (E880-888) & 162 & 1.2 & 1.4 & 1.1 & 2.9 & 2.8 & 7.9 & $1.46(1.31,1.63)$ \\
\hline Fire (E890-899) & 468 & 1.7 & 2.0 & 3.8 & 5.1 & 10.6 & 27.7 & $1.89(1.75,2.04)$ \\
\hline Submersion, suffocation and foreign bodies (E910-915) & 799 & 5.5 & 6.8 & 8.9 & 9.9 & 12.9 & 24.7 & $1.30(1.23,1.37)$ \\
\hline Other accidents (E916-928) & 259 & 0.7 & 1.6 & 3.1 & 3.9 & 4.4 & 7.1 & $1.43(1.30,1.57)$ \\
\hline Suicide (E950-959) & 47 & 0.9 & 0.3 & 0.4 & 0.6 & 0.8 & 1.0 & $1.19(0.96,1.47)$ \\
\hline Homicide (E960-969) & 182 & 1.2 & 1.2 & 2.4 & 2.3 & 2.7 & 7.1 & $1.39(1.25,1.56)$ \\
\hline Intent undetermined (E980-989) & 337 & 3.1 & 1.9 & 3.9 & 4.5 & 5.6 & 11.9 & $1.41(1.29,1.53)$ \\
\hline
\end{tabular}

* Excluding pedestrian and cyclist. 
these two causes of injury death together accounted for $37 \%$ of all child injury and poisoning deaths.

The accuracy of injury mortality data depends on the completeness and accuracy of death certification. Misclassification of injury death has been shown to occur, particularly among the elderly, but would be unusual in children. In this study, misclassification of social class may be more important. Social class was based on the Registrar General' scale. Because the scale is historically based on men's employment it is less applicable to women's occupations. Furthermore, because the scale excludes those without paid work, children in families where no adults are employed, including the children of lone parents with no paid work, are not included in these analyses. It is likely therefore that these analyses understate the true extent of socioeconomic differentials in child injury death rates.

Variations in Health postulated a number of explanations for observed variations in health including artefacts, health related mobility, biologic factors, health related behaviours, and differential access and use of health services.
However, these would not account for the mortality differentials in childhood injury. The explanation that is best supported by research evidence is that the gradients reflect differential exposure to health damaging physical and social environments. For fire deaths this entails the exposure of children to temporary accommodation and substandard housing, ${ }^{4}$ and for pedestrian deaths, the differential exposure of children to traffic. ${ }^{5}$ These differential exposures are in turn driven by widening income inequalities. Any strategy for the reduction of social class mortality differentials would have to address widening income inequality head on.

1 Department of Health. Variations in health. London: HMSO, 1995.

2 Office of Population Censuses and Surveys. Occupational mortality childhood supplement. Registrar general's decennial supplement for England and Wales, 1979-1980, 1982-83. London: HMSO, 1988. Series DS No 8.

3 Roberts I, Power C. Does the decline in child injury mortality vary by social class? A comparison of class specific mortality in 1981 and 1991. BMF 1996;313:784-6.

4 Home Office. Household fires in England and Wales: information from the 1994 British crime survey. London: Home Office, 1994.

5 Roberts I, Norton R, Taua B. Socioeconomic and ethnic differences in child pedestrian injury: the importance of exposure to risk. $\mathcal{f}$ Epidemiol Community Health 1996;50: $162-65$. 